\title{
Ethics and Stakeholder Engagement for Industry/Construction 4.0: A Systematic Review
}

DOI:

10.1007/978-3-030-26528-1_59

\section{Document Version}

Accepted author manuscript

Link to publication record in Manchester Research Explorer

\section{Citation for published version (APA):}

Okedara, K., Ejohwomu, O., \& Chan, P. (2019). Ethics and Stakeholder Engagement for Industry/Construction 4.0: A Systematic Review. In The Construction Industry in the Fourth Industrial Revolution: Proceedings of 11th Construction Industry Development Board (CIDB) Postgraduate Research Conference https://doi.org/10.1007/9783-030-26528-1_59

\section{Published in:}

The Construction Industry in the Fourth Industrial Revolution

\section{Citing this paper}

Please note that where the full-text provided on Manchester Research Explorer is the Author Accepted Manuscript or Proof version this may differ from the final Published version. If citing, it is advised that you check and use the publisher's definitive version.

\section{General rights}

Copyright and moral rights for the publications made accessible in the Research Explorer are retained by the authors and/or other copyright owners and it is a condition of accessing publications that users recognise and abide by the legal requirements associated with these rights.

\section{Takedown policy}

If you believe that this document breaches copyright please refer to the University of Manchester's Takedown Procedures [http://man.ac.uk/04Y6Bo] or contact uml.scholarlycommunications@manchester.ac.uk providing relevant details, so we can investigate your claim.

\section{OPEN ACCESS}




\title{
Construction Industry development Board Conference
}

MANCHESTER

1824

Ethics and Stakeholder Engagement for Industry/Construction 4.0: A Systematic Review

\author{
Okedara Kamil ${ }^{1}$, Obuks Ejohwomu ${ }^{1}$, Paul Chan ${ }^{2}$ \\ ${ }^{1}$ University of Manchester \\ School of Mechanical, Aerospace \& Civil Engineering (MACE) \\ (Tunde.okedara, Obuks.ejohwomu)@manchester.ac.uk \\ ${ }^{2}$ Deft University of Technology, Dept. of Management, Design and Construction Management \\ p.w.c.chan@tudelft.nl
}

\begin{abstract}
Industry 4.0 is an offshoot of the first, second and third industrial revolutions. Which is an indication of it is globalization. In the same vein, construction 4.0 which takes its context after the industry 4.0 is expected to lead to the fourth construction revolution? Ethics and stakeholder engagement have been individually studies and written about. Both industry and construction 4.0 require an ethical lens and an engagement pattern towards a rapid realization of their objectives. This paper quantitatively x-rays researchers' interests in the fields, and the subject areas so far covered in their studies. However, little or no studies have applied the ethical lens and engagement pattern into the revolutionary concepts. We applied systematic review method (the first in the field), to discover the linear and the polynomial nature of researches in the fields. This discoveries is hoped to open up further researches towards the rapid development of the fourth $\mathrm{I} \& \mathrm{C}$ revolutions through the application of ethics and stakeholder theories
\end{abstract}

Keywords: Industry 4.0, Construction 4.0, Ethics, Stakeholder engagement, Organizational Culture, Project, Programme \& Portfolio (PPP) 


\section{Construction Industry development Board Conference}

\section{Introduction}

Every endeavour requires a way to achieving success. This is what we refer to as the ethics needed for the success. This ethical approach requires an engagement pattern in achieving the successful outcomes[1]. The endeavour could be a project, programme or portfolio (PPP), it could be a concept such as "construction 4.0" or "industry 4.0". This paper, therefore researches into the extent of application of ethics and stakeholder concepts in both industry 4.0 and construction 4.0 ( I\&C 4.0) in order to ensure success of the revolutions. To understand this approach, we will look at the perspectives of success, engagement and ethics

Successful business, organizational or project management strategies have been variously discussed and described. Strategic management success may be measured through the use of scorecard which supports the alignment and management of corporate activities to their strategic relevance [2], while Figgie et.al.., (2002) highlighted the importance of strategic management aligning with corporate activities, others have also come up with various criteria that can cumulatively be necessary for envisaged success. For instance, it is averred that organizational success depends not only on how the organization makes the most of human competences, but also how it stimulates commitment to the organization [3]. The turbulent organizational environment is not left out of the discourse, this has been attributed to why organizations seek competitive advantage through organizational learning [4], in line with Namada, (2018), this learning, as part of knowledge management orientations, is said to comprise of 'the personal knowledge orientation' and 'organizational knowledge orientation' [5]. To further buttress the significance of business and organizational management success, process automation involving modelling processes and workflow [6], a fourth industrial revolution phase has been introduced. The term "industry 4.0", according to [7] was established ex-ante for a planned "4th industrial revolution", the term being a reminiscence of software versioning Methodology. Industry $\mathbf{4 . 0}$ which is also commonly referred to as the fourth industrial revolution is a name given to the current trend of automation and data exchange in manufacturing technologies. It includes cyber-physical systems, the Internet of things, cloud computing and cognitive computing. [8]. In the same vein, similar revolutions are being introduced to construction with "the fourth construction revolution tagged "construction 4.0". Though industry 4.0 describes the trend towards digitisation and automation of the manufacturing environment with potentials to benefits in terms of improvement in productivity and quality [9], the concept has not gained much attention in the construction industry [9] hence the need to not only ensure awareness but for researchers to dig deep into the area.

To attempt a broader understanding, ethics and stakeholder engagement will be presented in perspective of fourth industrial and construction revolutions, also known respectively as industry 4.0 and construction 4.0. Our definition for the purpose of this paper will also be stated. Stakeholder engagement and ethics have variously undergone definitions and perspectives over the years. Ethics could be rightness or wrongness of behaviour [10]. "The definition of ethics is said to be at abstract level [10] as it is difficult to have a consensus on what is morally right or wrong, good or bad, ethical or unethical". Despite the growth of ethics in business, business ethics researchers are yet to agree upon ethical perspective for the discipline [11]. [12], in their paper on human research ethics while quoting OED definition define ethics as "The codes of conduct or moral principles recognized in a particular profession, sphere of activity, relationship, or other context or aspect of human life. Attempting a definition for the purpose of this research, which I hope may transcend industry, project and business. Ethics can be a way of doing things or as a process culmination or path to an engagement outcome. This process culmination or path, when tested over time, can become norm in industry, business or project, it can also translate to culture or governance. When ethics is measured, sometimes in projects, to have given expected outcome or surpass expectation, the approach becomes adopted and becomes an ethical approach for such projects or business. This sometimes can become organizational norms or best practices, deviation from or adherence to those approaches at that point in time, may become an indication of good or bad practices etc.

Stakeholder engagement on the other hand, has gone through different phases of definitions, perspectives, and development of topics and terms Scholars have debated what it means to be a stakeholder, what obligations, if any, firms owe to stakeholders, and whether or not shareholders ought to be granted precedence over other stakeholders.[13]. In addition, 'Many accounts of stakeholder activities focus on the attributes of the organizations (or industry) or the attributes of the stakeholders rather than on the attributes of the relationship between organizations (or Industry) and stakeholders'. In the last few years, however, greater attention has been given to thinking about what it means to engage stakeholders (bracket mine) (Johnson- Cramer et al. 2003). As stakeholder ethics grows in recognition and in being a veritable tool for project and engagement success, thought about which actions firms or industry must or must not perform in order to meet philosophical, social, legal or environmental moral standards (this could be the fourth industrial or construction revolutions), greater 


\section{Construction Industry development Board Conference}

attention is now being paid to relationships between firms and its stakeholders .[13]. This has made approaches to stakeholder engagement to progress through some stages (Reed, 2008). Theories have therefore moved from awareness of the 1960s [14] to adding local angle to the debate in the 1970s (Pretty, 1995), from strategies of engagement in the $1980 \mathrm{~s}$ to increasing community participation and democratizing engagement in stakeholder governance [15]

With the above background on ethics, stakeholder engagement, industry 4.0 and construction 4.0 , there is the need to examine the essence of this review and the research question. The growing trend in industry 4.0 and the consequential increased interest in construction 4.0. Both industry and construction (I\&C) 4.0 can be subjected to process ethics which will not only enhance their evolution, but also has the tendency to catalyse growth, replicability and development in the fields. The twin area of ethics and stakeholder engagement have the capacities to establish proper record of developments and a path that can be followed and replicated for the realisation of the objectives fourth $\mathrm{I} \& \mathrm{C}$ revolutions

To this end, the following research question, as a preliminary or foundation setting for further research in the field of ethics, stakeholder engagement, and industry 4.0 and construction 4.0 are set for this systematic review objective.

RQ! How has researchers' interest in the field been growing?

RQ2: How has this growth impacted other subject area and how indeed it has affected the globalization of I \& C $4.0 \mathrm{~s}$

Before we venture into answering the research questions, let me quickly add that this is the first research linking ethics, stakeholder engagement, industry 4.0 and construction 4.0 and it is also the first systematic review in the fields.

\section{Methodology}

"To answer the research questions in the introduction above, the literatures on ethics, stakeholder engagement, industry 4.0 and construction 4.0 were systematically reviewed and synthesised. Other literatures were also studied in other to give an impactful analysis of the 26 papers under review. Systematic reviews , which originated from the medical and health sciences, are a thorough and transparent way of mapping and assessing the evidence in a particular topic area [16]. The adoption was after a thorough review of other methods such as bibliometric analysis [17] and analysis of meta - narratives in the literature [18]. these other methods have been stated to rely "on quantitative methods to identify keyword frequencies and the changing trends of keyword associations." [19]. To further justify our choice of review, aside from systematic review being known for its transparency and being an evidence-based approaches that identify key scientific contributions to a field and differ from narrative reviews by adopting a replicable, scientific and transparent process (Tranfield et al., 2003), it also allow researchers to study the strength of the published evidence while still attempting to remain as natural and unbiased as possible. This is possible because of the inherent evidences in the review analysis and synthesis. When facts are presented, scientific conclusions becomes easier. Though the process may be cumbersome and detailed, systematic review, according to Tranfield et.al.., (2003), systematic review is still acknowledged as the most efficient for identifying and evaluating literatures. In addition, systematic reviews, aside from not only being important for advancing the field of study, it is also a veritable tool for advancing and informing management practice [20].’[1]

\subsection{Systematic Literature Review Approach}

In the process of reviewing the empirical evidences in the existing literature, systematic review was considered as best and comprehensive option for identifying the gaps in ethic in stakeholder engagement, this was also buttressed by Transfield et al and Booth et al [16][21]. This review was done with the protocol inError! Reference source not found. 


\section{Construction Industry development Board Conference}

Stage I-Planning the review

Phase 0 - Identification for the need for a review

Phase 1 - Preparation of a proposal for a review

Phase 2 - Development of a review protocol

Stage II-Conducting a review

Phase 3 - Identification of research

Phase 4 - Selection of studies

Phase 5 - Study quality assessment

Phase 6 - Data extraction and monitoring progress

Phase 7 - Data synthesis

Stage III-Reporting and dissemination

Phase 8 - The report and recommendations

Phase 9 - Getting evidence into practice

Figure 1: Stages of a Systematic Review [Source: Tranfield, Denyer and Smart (2003)]

For the purpose of this paper, Error! Reference source not found. has been collapsed to the five steps below, which the review is subjected to:

$>$ Identification of research;

$>$ selection of studies;

$>$ Study quality assessment;

$>$ data extraction and monitoring progress; and

$>$ data synthesis

The process of arriving at the 19 document for final review is analytically captured in the flowchart

Figure 2: Flow chart showing search and analytical process. This makes the process transparent and it confirms the rigour and reliability of the systematic review[16]

The coding structure for the systematic review follows the Tranfield protocols. The basis for the coding, amongst others, is to ensure that all vital information are well captured in the coding system and hence in the analysis. Microsoft excel was utilized for the coding step of the systematic review The 18 papers were subjected to the coding structure (as in Error! Reference source not found.) utilization of Microsoft excel made the coding easy as well as the analysis. The coding uses the bibliometric details such as year of publication, details of authors, journal and article title. In addition, further categorization in terms of the study sector, author's nationality and in some cases, sample size of the research. This sometimes makes it easy to observe saturation trend across research articles. This 26 studies that scaled through to full analysis and synthesis also scaled through the inclusion and exclusion, as shown in criteria when subjected it

\section{Keyword search:}

Search databases: Web of science, Scopus and Google scholar yielding (with google scholar returning a total of 2905)

Removal by elimination of duplicates, in title filter elimination in Google scholar and unrelated results in 


\section{Construction Industry development Board Conference}

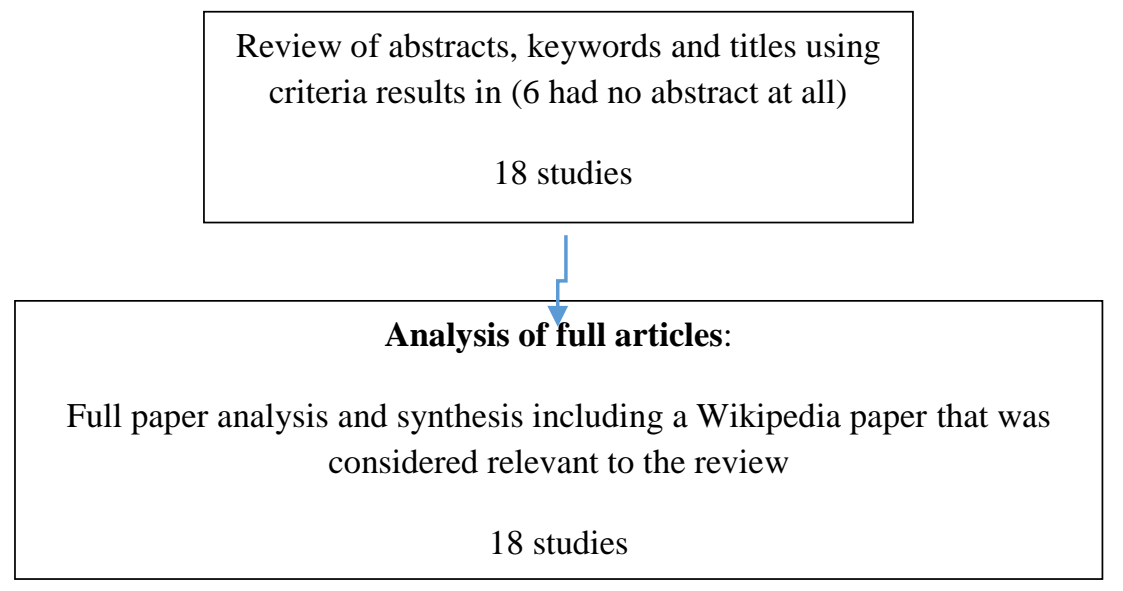

Figure 2: Flow chart showing search and analytical process

The review commenced with identification of research. In order to increase the credibility of the research, we did not impose any time limitation or be limited to a time in the past. The result is all the data bases could return. To also increase our review horizon and identify literatures, we did not limit our types of publications. The types returned were what the databases could return back during each search. Our search included reviews, journal articles, book chapters, conference papers. This is a standard practice in review studies, since these sources are considered 'certified knowledge' and enhance the results' reliability [22]. Our conclusion that this is the first study and review in ethics, stakeholder engagement, industry 4.0 and construction 4.0 was enhanced by the outcome of our search results. This further created the need to keep varying our search keywords (as most databases were returning zero results). In all the databases, the search strings "ethics" and "stakeholder engagement" and "industry 4.0" on one hand yielded zero result except for google scholar that brought 75 results but eventually gave zero when the "in title" option was used and the search strings "ethics" and "stakeholder engagement" and "construction 4.0" on the other, also yielded zero results from all the databases. To enhance our review quality, the following combination of search string was finally adopted "ethics" AND "industry 4.0" and one hand and "construction 4.0" were separately searched for the review. We applied the search string to the titles, keywords and abstracts of publications in academic databases. In particular, we used Scopus, Web of Science and Google scholar databases to search for all publications whose topics cover at least one keyword from the selected sets of search string. These databases were chosen for their known broad and multidisciplinary scope, their popularity in academia and are reputed for being the most commonly used sources for review studies [23], [24]

\subsection{Inclusion and Exclusion Criteria}

To arrive at the 18 studies for review, the following inclusion and exclusion criteria were used. These are captured in table below:

Table 1: Table Showing Inclusion and Exclusion Criteria

\begin{tabular}{|l|l|}
\hline Exclusion & Inclusion \\
\hline No Abstract & Articles \\
\hline $\begin{array}{l}\text { Unrelated } \\
\text { publications }\end{array}$ & Book Chapters \\
\hline & Conference paper \\
\hline & Review Paper \\
\hline & Workshop output \\
\hline & Wikipedia \\
\hline
\end{tabular}

\section{Results, Findings and Discussion}

The review, as previously suggested, brought out series of analytical outputs that would not just determine the future direction of research in the field of ethics, industry 4.0 and construction 4.0 (ESEI\&C 4.0), it also brings to the fore, relational and deductive researches that will extensively contribute to both practice and academics and may lead to rapid development in the field. To quantitatively confirm that development and growth in both industry 4.0 and construction 4.0 has not been studied in relation to the needed 


\section{Construction Industry development Board Conference}

ethics and stakeholder engagement approaches, we would begin with a frequency analysis of our researches in the fields.

\subsection{Frequency Analysis}

The frequency analysis is a veritable tool to projecting, descriptively and graphically, the pattern of the review over the past years. This can be an indication of either growing or declining interest in the discourse of ethics in stakeholder engagement, industry 4.0 and construction 4.0

The search results from the databases brought the earliest time studies were conducted in the field to be 2015 , which is also a confirmation that both industry 4.0 and construction 4.0 are recent additions into research. From Figure 3: Frequency Analysis - Linear above, we can also see that it is an emerging field. The r-square value of 0.6563 is an indication of its still low emergence.

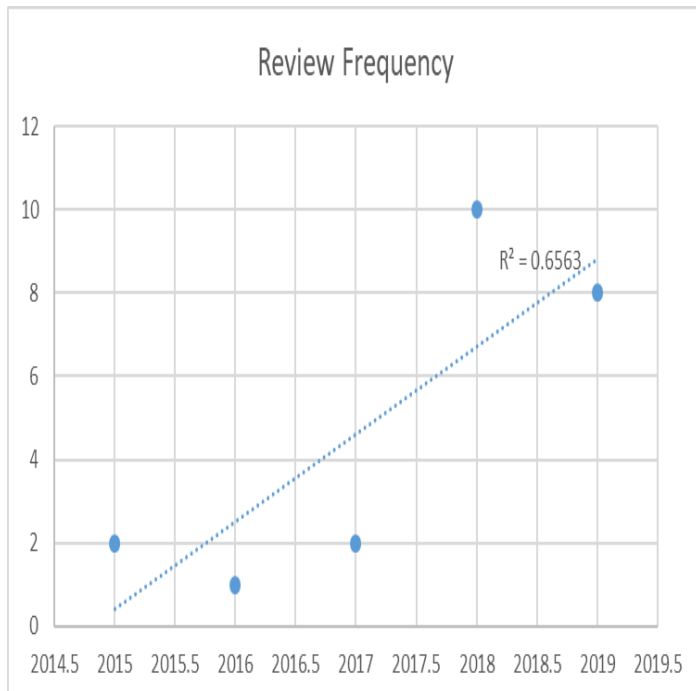

Figure 3: Frequency Analysis - Linear

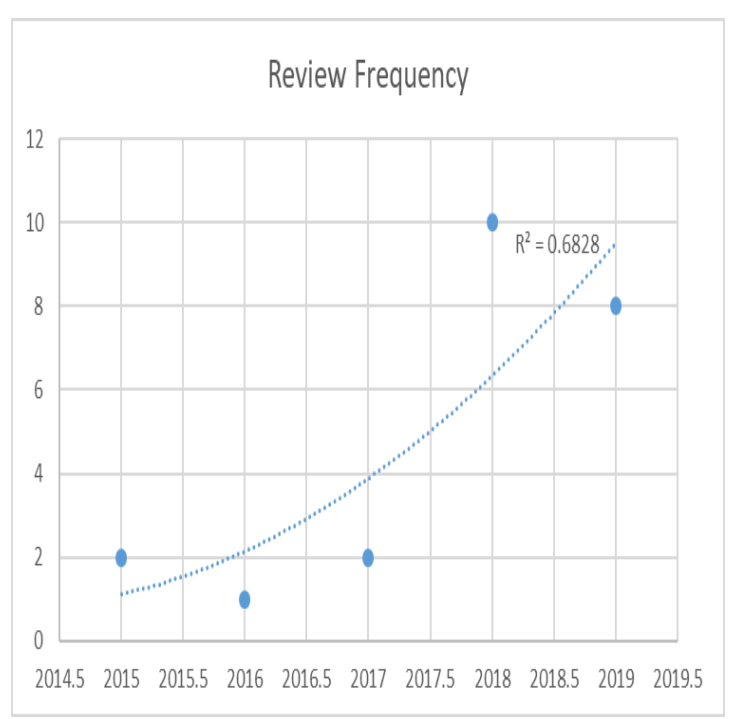

Figure 4: Frequency Analysis - Polynomial

Above notwithstanding, if we attempt an analysis of

Figure 4: Frequency Analysis Polynomial, we would observe that the r-square is higher than Figure 3: Frequency Analysis - Linear. This is an indication that the frequency is more polynomial than linear. This can be attributed to the inconsistency in the interest researcher have shown in the field. The highest study of 10 studies was in 2018 which was a leap jump from 2 in 2017. Though 2019 has not ended we can't predict what the 2019 pattern will end up with (the authors expect an increase because there are already 8 studies in less than half of the year). The pattern that gave rise to a higher polynomic r-square vale can be seen from studies from 2015 to 2018

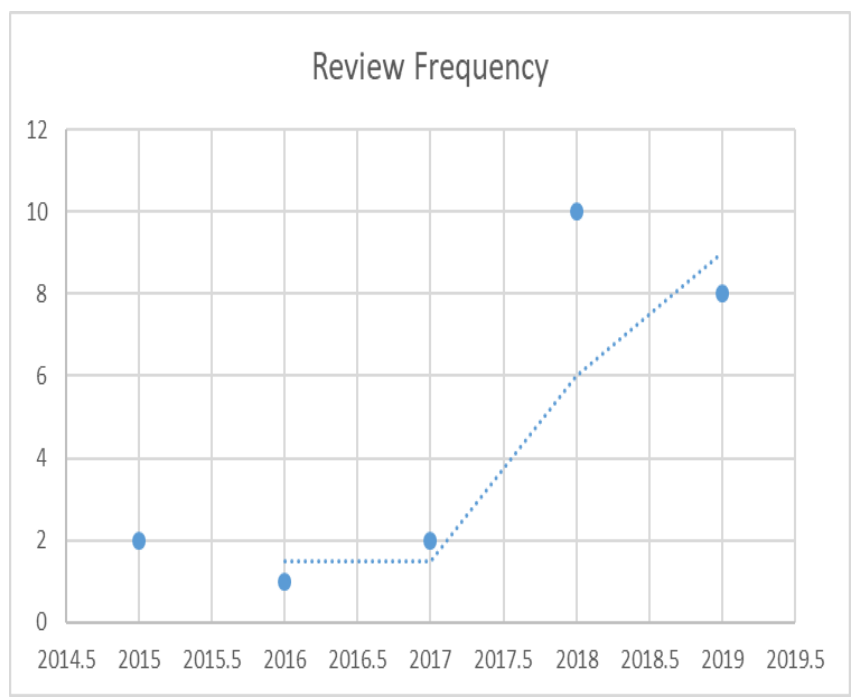

Table 2 : Review Analysis of Subject Areas 


\section{Construction Industry development Board Conference}

Figure 5: Frequency Analysis - Moving Average

The authors also applied the moving average as shown in

to indicate that though the field is emerging, the interest researchers are showing in the fields is still low - with the lowest average being only one study in 2016 and highest of nine studies in 2019. (Kindly note that these studies are predominantly in education and are not in ethics field). This makes the subject area analysis necessary to strengthen our conclusions

\subsection{Subject Area Analysis}

With the frequency analysis in 2 above, there is the need to analyse further and see the subject areas researchers have

\begin{tabular}{|l|r|}
\hline Review Subject Area & Frequency \\
\hline Advanced Process control & 1 \\
\hline Automation & 1 \\
\hline Construction 4.0 & 1 \\
\hline Cybersecurity & 1 \\
\hline Constructio (Dam \& Steel) & 2 \\
\hline Earthmoving Machinery & 2 \\
\hline Education & 3 \\
\hline Hunan-Computer Interaction & 1 \\
\hline Innovation & 1 \\
\hline Robotics, AI etc & 1 \\
\hline Sustainable Development & 1 \\
\hline Not defined subject Area & 8 \\
\hline Total & $\mathbf{2 3}$ \\
\hline
\end{tabular}
been studying or expanding the frontiers of knowledge in relation to how ethics and stakeholder engagement are being applied in the field of industry 4.0 and construction 4.0. This will further show how the field is developing and how researchers are spreading the application or implementation of industry 4.0 and construction 4.0 to various fields of study and by implication its level of globalization.

Table 2 : Review Analysis of Subject Areas shows the breakdown of subject areas that both industry 4.0 and construction 4.0 are being studied within the context of the review. The pictorial analysis of this table can be seen in the figure below

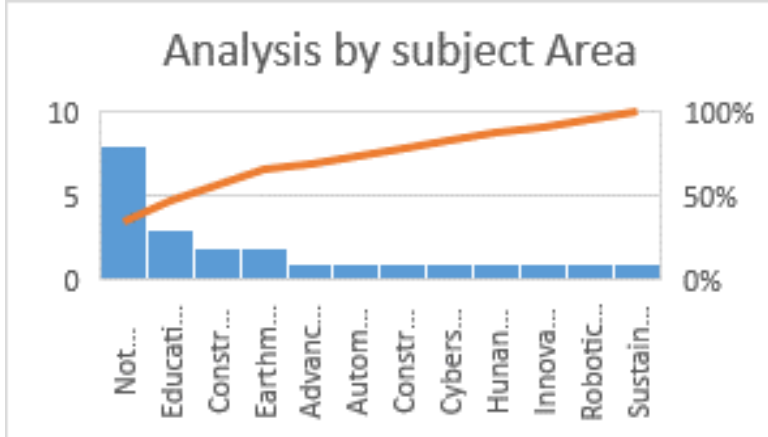

Figure 6: Subject Areas Analysis

Both Table 2 : Review Analysis of Subject Areas and Figure 6: Subject Areas Analysis give a clearer pattern of emerging subject fields being studied. The highest study goes to an area the authors could not readily attribute to a subject concern hence the tag "undefined". Let's quickly add that the publications without abstracts are included in this categorization. The second in the series is the academic or education field. This predominantly focus on amending curriculum and or preparing academics with the probable challenges envisaged by the movement to fourth industrial revolution. This can be seen in the following included discus: Learning Framework in the Industrial Age 4.0 in Higher Education [25], Vocational Education and Training of construction machinery operators in Spain (Corral , 2018), On a Frame Work of Curriculum for Engineering Education 4.0 [27], Fourth Industrial Revolution and the future of Engineering: Could Robots Replace Human Jobs? How Ethical Recommendations can Help Engineers Rule on Artificial Intelligence [28]. These titles clearly show the focus of the study in the educational field. This brings us to the second conclusion that industry 4.0 and construction 4.0 study requires expansion of fields and subject areas. So far, within the limits of this analysis, industry and construction 4.0 studies has been restricted to only eleven clearly defined fields. It may interest us that none of this studies is ethics or stakeholder engagement related

\section{Conclusion}

From the forgoing, the following conclusions can be derived from the systematic review study:

1. That researchers have not yet shown interest in ethics and stakeholder engagement in both industry 4.0 and construction 4.0. This therefore calls for concerted efforts at establishing an ethical approach to both fourth industrial and construction revolutions. Further studies in this field may reveal the path 


\section{Construction Industry development Board Conference}

rapid growth and replication into other sectors. Lesson learnt, as an ethical approach is developmental tool [29]

2. From the coverage of the subject areas, it can be seen that the highest defined interest is in the education filed and has more to do with curricular and framework setting. This is also a clarion call for industrial and construction researchers and practitioners to look deeper into studies that will enhance the rapid development of industry and construction 4.0 by bringing out the ethics of engagement in core industries and construction with a view to enhancing rapid development and expansion of the fourth industrial and construction revolutions

5 References

[1] E. O. Okedara Kamil, Chan Paul, Collinge Bill, "Review, Ethics in stakeholder engagement for successful organizational and Project Management: A systematic," in British Academy of Management, 2019.

[2] F. Figge, T. Hahn, S. Schaltegger, and M. Wagner, "The sustainability balanced scorecard - Linking sustainability management to business strategy,” Bus. Strateg. Environ., vol. 11, no. 5, pp. 269-284, 2002.

[3] K. Tripathi and M. Agrawal, "Competency Based Management In Organizational Context:," Glob. J. Financ. Manag., vol. 6, no. 4, pp. 349-356, 2014.

[4] J. M. Namada, "Organizational Learning and Competitive Advantage," Handb. Res. Knowl. Manag. Contemp. Bus. Environ., p. 19, 2018.

[5] R. Sanchez, “Knowledge Management and Concepts for Theory and Practice,” pp. 29-30, 2006.

[6] M. Zur Muehlen, "Organizational Management in Workflow Applications - Issues and Perspectives," Inf. Technol. Manag., vol. 5, no. 3/4, pp. 271-291, 2004.

[7] A. Lele and Wikipedia, "Industry 4.0," Wkipedia, 2019. [Online]. Available: https://en.wikipedia.org/wiki/Industry_4.0. [Accessed: 19-May-2019].

[8] Wikipedia, "Industry 4.0," Wkipedia, 2019. [Online]. Available: https://en.wikipedia.org/wiki/Industry_4.0. [Accessed: 19-May-2019].

[9] T. D. Oesterreich and F. Teuteberg, "Understanding the implications of digitisation and automation in the context of Industry 4.0: A triangulation approach and elements of a research agenda for the construction industry," Comput. Ind., vol. 83, pp. 121-139, 2016.

[10] P. V. Lewis, “Defining 'business ethics': Like nailing jello to a wall," J. Bus. Ethics, vol. 4, no. 5, pp. 377-383, 1985.

[11] D. Robin, “Toward an applied meaning for ethics in business,” J. Bus. Ethics, vol. 89, no. 1, pp. 139$150,2009$.

[12] E. A. Ian Stewart, Francis Fenn, "Human research ethics - is construction management research concerned?," Constr. Manag. Econ., p. 11, 2017.

[13] J. Noland and R. Phillips, "Stakeholder engagement, discourse ethics and strategic management," Int. J. Manag. Rev., 2010.

[14] S. R. Arnstein, “A Ladder Of Citizen Participation,” J. Am. Plan. Assoc., vol. 35, no. 4, pp. 216-224, 1969.

[15] E. Ortas, I. Álvarez, and A. Garayar, "The environmental, social, governance, and financial performance effects on companies that adAopt the United Nations Global Compact," Sustain., vol. 7, no. 2, pp. 1932-1956, Feb. 2015. 


\section{Construction Industry development Board Conference}

[16] D. Tranfield, D. Denyer, and P. Smart, "Towards a methodology for developing evidence-informed management knowledge by means of systematic review," Br. J. Manag., vol. 14, no. 3, pp. 207-222, 2003.

[17] J. Pollack and D. Adler, "Emergent trends and passing fads in project management research: A scientometric analysis of changes in the field," Int. J. Proj. Manag., vol. 33, no. 1, pp. 236-248, 2015.

[18] M. Padalkar and S. Gopinath, "Six decades of project management research: Thematic trends and future opportunities,” Int. J. Proj. Manag., vol. 34, no. 7, pp. 1305-1321, 2016.

[19] P. W. Chan and O. Ejohwomu, "How does project management relate to productivity? A systematic reviewed of published evidence," no. July, p. 40, 2018.

[20] S. Cummings and U. Daellenbach, "A Guide to the Future of Strategy?," Long Range Plann., vol. 42, no. 2, pp. 234-263, 2009.

[21] A. Booth, D. Papaioannou, and A. Sutton, Systematic Approaches to a Successful Literature Review. London: SAGE Publications Ltd, 2013.

[22] S. Saggese, F. Sarto, and C. Cuccurullo, "Evolution of the Debate on Control Enhancing Mechanisms: A Systematic Review and Bibliometric Analysis," Int. J. Manag. Rev., vol. 18, no. 4, pp. 417-439, 2016.

[23] E. M. Tachizawa and C. Y. Wong, "Towards a theory of multi-tier sustainable supply chains: A systematic literature review," Supply Chain Manag., vol. 19, pp. 643-653, 2014.

[24] P. Beske-Janssen, M. P. Johnson, and S. Schaltegger, "20 Years of Performance Measurement in Sustainable Supply Chain Management - What Has Been Achieved?," Supply Chain Manag., vol. 20, no. 6, pp. 664-680, 2015.

[25] Winanti, F. L. Gaol, T. A. Napitupulu, H. Soeparno, and A. Trisetyarso, "Learning Framework in the Industrial Age 4.0 in Higher Education," in 2018 INDONESIAN ASSOCIATION FOR PATTERN RECOGNITION INTERNATIONAL CONFERENCE (INAPR), 2018, pp. 227-232.

[26] E. Corral Álvarez, "Vocational Education and Training of construction machinery operators in Spain ," Carreteras, vol. 4, no. 222, pp. 68-72, 2018.

[27] L. Jeganathan, A. N. Khan, J. K. Raju, and S. Narayanasamy, "On a Frame Work of Curriculum for Engineering Education 4.0," in 2018 WORLD ENGINEERING EDUCATION FORUM - GLOBAL ENGINEERING DEANS COUNCIL (WEEF-GEDC), 2018.

[28] M. B. Hoeschl, T. C. D. Bueno, and H. C. Hoeschl, "Fourth Industrial Revolution and the future of Engineering: Could Robots Replace Human Jobs? How Ethical Recommendations can Help Engineers Rule on Artificial Intelligence," in 2017 7TH WORLD ENGINEERING EDUCATION FORUM (WEEF), 2017, pp. 21-26.

[29] J. T. W. Ching, "To assess the feasibility of constructing " Developmental Relationships " as a relevant mentoring model for the Diploma in Business \& Social Enterprise," 2011.

\section{Full Review Reference}

[1] E. O. Okedara Kamil, Chan Paul, Collinge Bill, "Review, Ethics in stakeholder engagement for successful organizational and Project Management: A systematic," in British Academy of Management, 2019.

[2] F. Figge, T. Hahn, S. Schaltegger, and M. Wagner, "The sustainability balanced scorecard - Linking sustainability management to business strategy," Bus. Strateg. Environ., vol. 11, no. 5, pp. 269-284, 2002. 


\section{Construction Industry development Board Conference}

[3] K. Tripathi and M. Agrawal, "Competency Based Management In Organizational Context:," Glob. J. Financ. Manag., vol. 6, no. 4, pp. 349-356, 2014.

[4] J. M. Namada, "Organizational Learning and Competitive Advantage," Handb. Res. Knowl. Manag. Contemp. Bus. Environ., p. 19, 2018.

[5] R. Sanchez, “Knowledge Management and Concepts for Theory and Practice," pp. 29-30, 2006.

[6] M. Zur Muehlen, "Organizational Management in Workflow Applications - Issues and Perspectives," Inf. Technol. Manag., vol. 5, no. 3/4, pp. 271-291, 2004.

[7] A. Lele and Wikipedia, "Industry 4.0," Wkipedia, 2019. [Online]. Available: https://en.wikipedia.org/wiki/Industry_4.0. [Accessed: 19-May-2019].

[8] Wikipedia, "Industry 4.0," Wkipedia, 2019. [Online]. Available: https://en.wikipedia.org/wiki/Industry_4.0. [Accessed: 19-May-2019].

[9] T. D. Oesterreich and F. Teuteberg, "Understanding the implications of digitisation and automation in the context of Industry 4.0: A triangulation approach and elements of a research agenda for the construction industry," Comput. Ind., vol. 83, pp. 121-139, 2016.

[10] P. V. Lewis, “Defining 'business ethics': Like nailing jello to a wall," J. Bus. Ethics, vol. 4, no. 5, pp. 377383, 1985.

[11] D. Robin, "Toward an applied meaning for ethics in business," J. Bus. Ethics, vol. 89, no. 1, pp. 139-150, 2009.

[12] E. A. Ian Stewart, Francis Fenn, "Human research ethics - is construction management research concerned?," Constr. Manag. Econ., p. 11, 2017.

[13] J. Noland and R. Phillips, "Stakeholder engagement, discourse ethics and strategic management," Int. J. Manag. Rev., 2010.

[14] S. R. Arnstein, “A Ladder Of Citizen Participation,” J. Am. Plan. Assoc., vol. 35, no. 4, pp. 216-224, 1969.

[15] E. Ortas, I. Álvarez, and A. Garayar, "The environmental, social, governance, and financial performance effects on companies that adAopt the United Nations Global Compact," Sustain., vol. 7, no. 2, pp. 1932-1956, Feb. 2015.

[16] D. Tranfield, D. Denyer, and P. Smart, "Towards a methodology for developing evidence-informed management knowledge by means of systematic review," Br. J. Manag., vol. 14, no. 3, pp. 207-222, 2003.

[17] J. Pollack and D. Adler, "Emergent trends and passing fads in project management research: A scientometric analysis of changes in the field," Int. J. Proj. Manag., vol. 33, no. 1, pp. 236-248, 2015.

[18] M. Padalkar and S. Gopinath, "Six decades of project management research: Thematic trends and future opportunities," Int. J. Proj. Manag., vol. 34, no. 7, pp. 1305-1321, 2016.

[19] P. W. Chan and O. Ejohwomu, "How does project management relate to productivity? A systematic reviewed of published evidence," no. July, p. 40, 2018.

[20] S. Cummings and U. Daellenbach, "A Guide to the Future of Strategy?," Long Range Plann., vol. 42, no. 2, pp. 234-263, 2009.

[21] A. Booth, D. Papaioannou, and A. Sutton, Systematic Approaches to a Successful Literature Review. London: SAGE Publications Ltd, 2013.

[22] S. Saggese, F. Sarto, and C. Cuccurullo, "Evolution of the Debate on Control Enhancing Mechanisms: A Systematic Review and Bibliometric Analysis," Int. J. Manag. Rev., vol. 18, no. 4, pp. 417-439, 2016.

[23] E. M. Tachizawa and C. Y. Wong, "Towards a theory of multi-tier sustainable supply chains: A 


\section{Construction Industry development Board Conference}

systematic literature review," Supply Chain Manag., vol. 19, pp. 643-653, 2014.

[24] P. Beske-Janssen, M. P. Johnson, and S. Schaltegger, "20 Years of Performance Measurement in Sustainable Supply Chain Management - What Has Been Achieved?," Supply Chain Manag., vol. 20, no. 6, pp. 664-680, 2015.

[25] Winanti, F. L. Gaol, T. A. Napitupulu, H. Soeparno, and A. Trisetyarso, "Learning Framework in the Industrial Age 4.0 in Higher Education," in 2018 INDONESIAN ASSOCIATION FOR PATTERN RECOGNITION INTERNATIONAL CONFERENCE (INAPR), 2018, pp. 227-232.

[26] E. Corral Álvarez, "Vocational Education and Training of construction machinery operators in Spain ," Carreteras, vol. 4, no. 222, pp. 68-72, 2018.

[27] L. Jeganathan, A. N. Khan, J. K. Raju, and S. Narayanasamy, "On a Frame Work of Curriculum for Engineering Education 4.0," in 2018 WORLD ENGINEERING EDUCATION FORUM - GLOBAL ENGINEERING DEANS COUNCIL (WEEF-GEDC), 2018.

[28] M. B. Hoeschl, T. C. D. Bueno, and H. C. Hoeschl, "Fourth Industrial Revolution and the future of Engineering: Could Robots Replace Human Jobs? How Ethical Recommendations can Help Engineers Rule on Artificial Intelligence," in 2017 7TH WORLD ENGINEERING EDUCATION FORUM (WEEF), 2017, pp. 21-26.

[29] J. T. W. Ching, "To assess the feasibility of constructing " Developmental Relationships " as a relevant mentoring model for the Diploma in Business \& Social Enterprise," 2011. 